\title{
Evaluation of temporary architecture in Iraq (An applied study of camps for the displaced)
}

\author{
Assist. Chief Eng. Haidar Adnan Nsaif ${ }^{1}$, Assist. Pro.Dr. Abdullah Saadoon Salman ${ }^{2}$, \\ Lecturer. Dr. Enas Salim AbdulAhaad ${ }^{3}$ \\ \{hk_kz@yahoo.com ${ }^{1}$, abdullah.asadoon@yahoo.com ${ }^{2}$,enas_salim76@yahoo.com $\left.{ }^{3}\right\}$ \\ Univ. of Technology - Dep. Of Architecture /Iraq ${ }^{1}$, Univ. of Technology - Dep. Of \\ Architecture/Iraq ${ }^{2}$, Univ. of Technology - Dep. Of Architecture/Iraq ${ }^{3}$
}

\begin{abstract}
The demands of temporary architecture have become more urgent in recent decades for reasons related to some of the environmental disasters, civilian and military crises, which required immediate architectural solutions. The research focuses on the displaced person sector in Iraq after the registered number of refugees exceeded three million, and the research problem was determined by the "necessity of investigating temporary housing units locally and evaluating them according to the pillars of temporary architecture". The descriptive-analytical method is relied on, by clarifying the concept of temporary architecture and defining the pillars of the architecture of the displaced. Then, introducing a theoretical framework that specifies detailed indicators that can be adopted for evaluation. After that, analyzing three types of temporary housing units constructed locally in Iraqi Kurdistan (tents, site construction, prefabricated building) to reach the results that showed the shortcomings of the local temporary units in meeting environmental and privacy needs.
\end{abstract}

Keywords: temporary architecture, Displaced, camps, Tents, prefabricated.

\section{Introduction}

The temporary architecture provides many solutions to societal needs as a result of disasters and conditions beyond control, such as, conflicts and wars that have broad and rough impacts and cause death and property loss. The enormous number of damaged and fallen structures after the fiasco makes a lodging issue that necessities urgent consideration. The residence is the main problem in the aftermath of any disaster due to its effects on the social, physical, psychological and ecological aspects. The emergency shelter conditions established for disaster victims focus on overcoming the post-disaster negative conditions and defending victims from peripheral effects. Building temporary housing is a fundamentally different process from normal.

The research begins with the definition of the concept of temporary architecture, and mentioned studies that dealt with this concept down to the research problem, then building the theoretical framework items, then measuring the possible values by choosing a sample of the elected projects to arrive at a set of results and conclusions related to the research. 


\section{The concept of temporary architecture:}

It represents the structure that meets requests for temporary services for a limited period that may be lengthened or shortened depending on the completion of the job for which they are established [1]. As for the forms of temporary architecture, see Figure 1 :

- Adaptive reuse architecture: It represents permanent structures whose use changes over time. Some permanent structures are not used continuously or use changes. Examples include theaters, exhibition and event centers, as well as abandoned or vacant spaces [2].

- Mobility architecture: It represents portable structures that can be dismantled, moved, and assembled. Examples include tents, caravans, installations, and exhibitions.

- Single-use architecture: These are one-time structures that are disposed of after no-need is required. Examples include exhibitions, one-time events, promotions, launches [3].

- Interactive Architecture: Represents structures that grow or change shape or composition, position, or condition over time. Examples include flexible interactive space, open construction systems, and ecological buildings [4].

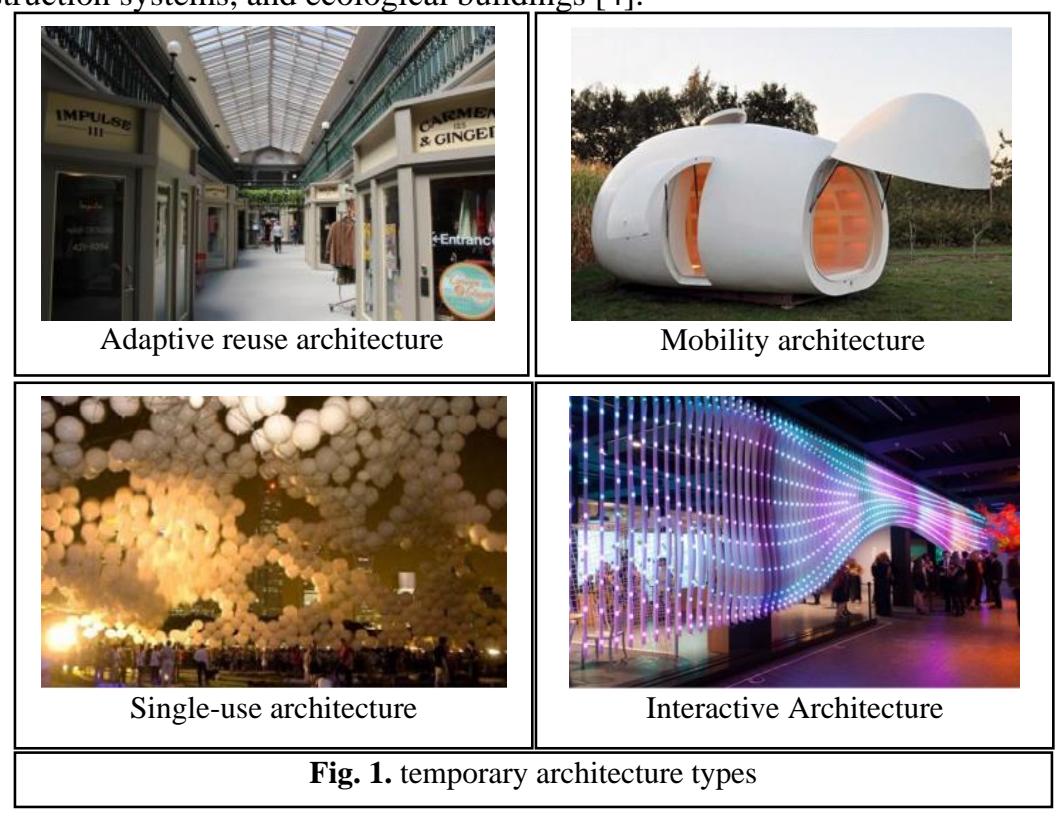

As for the temporary architecture of the displaced, it represents temporary facilities for housing citizens in special circumstances, such as victims of earthquakes and floods, or victims of disasters and wars. The disaster management process requires a group of national, local and international organizations such as the United Nations and the Red Cross who should be able to respond to situations in a concerted effort. Every disaster is a unique event that affects societies in very different ways. Because relief and recovery take so long, strategic planning is crucial to identifying the people most affected. Managing these risks requires some steps when affected societies start to rebuild their lives after disasters. The review of post-disaster conditions in many states leads us to move directly to the permanent housing stage in the emergency stage is impossible. Therefore, we should find another stage that signifies the duration from the emergency aid phase until regular living is carried out in permanent houses, and this is what we 
call "a temporary stage". Thus, we can analyze the post-disaster period into three phases, see Figure2:

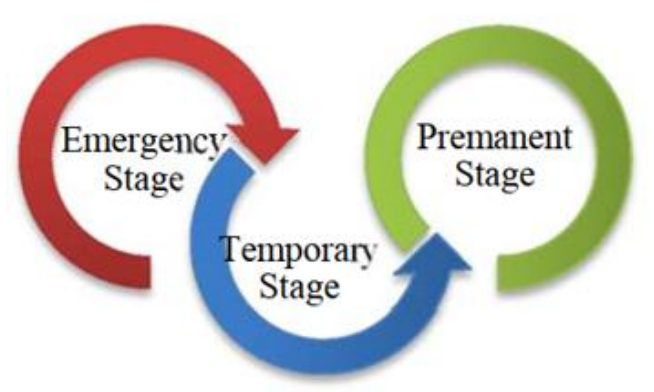

Fig.2. illustrates the stages of the post-disaster period

- The emergency phase: It is the stage in which displaced victims make their own accommodations with emergency shelters by managements or donations.

- The temporary phase: it should start directly after the emergency phase or the disaster, and the process remains until the permanent houses are finished. At this stage, the housing is dissolved by the temporary housing. The period for the rehabilitation phase is a result of the provision of permanent housing and is not specified in advance. In some cases of delay in the reconstruction phase, the interim phase can last up to 25 years. In these cases, temporary homes perform temporary tasks associated with the use and period.

- The permanent phase: develops or rebuild a disaster-stricken area or rebuild many complex residentials and aims to offer in a short period of time suitable permanent shelters for victims [5].

\section{Refugee architecture and its types:}

They represent temporary projects that are shaped in response to issues and concerns, such as remedies, in the five years after the major earthquake that struck the city of Christchurch in 2011, which he described as places to gather but became ineffective or economically costly. The reason for this is that it destroys long-term plans and undermines them if they are implemented without a dimensional time plan, which has an impact on users, and that contradicts the possibilities of temporary architecture that opens opportunities for participation and change with users through coordination between their immediate and expected needs. In addition, the process of making buildings in their time and place associated with a circumstance, through which some sense of ownership can be created among the afflicted and displaced persons, and in the event of difficult and sometimes catastrophic conditions on the economic, social and natural levels such as famines, wars and earthquakes, the permanent building becomes a costly matter It is difficult to achieve, therefore the most important requirement is to provide shelter to preserve life and protect from the elements of nature with the importance of securing a building of design quality to adapt to future changes while emphasizing the importance of technology in these buildings in terms of how we build [6]. 
(Roberto) outlined two prevailing needs in refugee architecture, the first: compliance with the requirements of reducing the impact on the ground, protecting resources and preserving the environmental balance, as a structure that must be resolved without waste, so that the material resources from which it was made can be reused, and that the creativity of the temporary structure needs to The ability to reflect and operate construction as innovation in the process itself and not as product innovation, through systematic procedures for planning, design and construction. New patterns emerged from urgent alternative spaces known as "emergency spaces" to find design solutions in housing, education and health. Attempts were made to find sustainable alternative spaces temporarily in simple ways and materials without the need to add additional design and economic burdens[7].

Among the most important refugee buildings include: tents, floor buildings, prefab shelters and container housing, and tents are the simplest and least expensive, while the ground buildings are very appropriate to the situation in which there is slight budget for construction and after the disaster, the victims may not leave the place, which can It continues as permanent houses. Ready shelters possible to be used to construct a large number of IDPs camps, who need so many shelters in a short period, and this form can only be used by governments or donations due to its high budget. Finally, Container house is the most widespread temporary housing in the world, and it is characterized by its permanent nature, durability and continuity of use, although it was designed to be a means of transporting and loading goods, for its flexibility it can be divided to sub-units so it can be transported to many places as need. The dimensions of the container must fulfill the prerequisite to provide spaces (kitchen, bathroom, and living room) and their formation in the applications of containers. These three functional zones can be centralized organized in one container unit; the container units act as bedrooms and then increase or decrease according to the number of family members, see Figure 3, and the walls can be divided so that they are placed to define areas, lighting windows. The most important feature of a typical housing container is that designers can present several types of temporary shelters by these kinds of container and if a rise happen in the number of users, it can be modified to allow grouping and devising between multiple units according to specific housing needs.
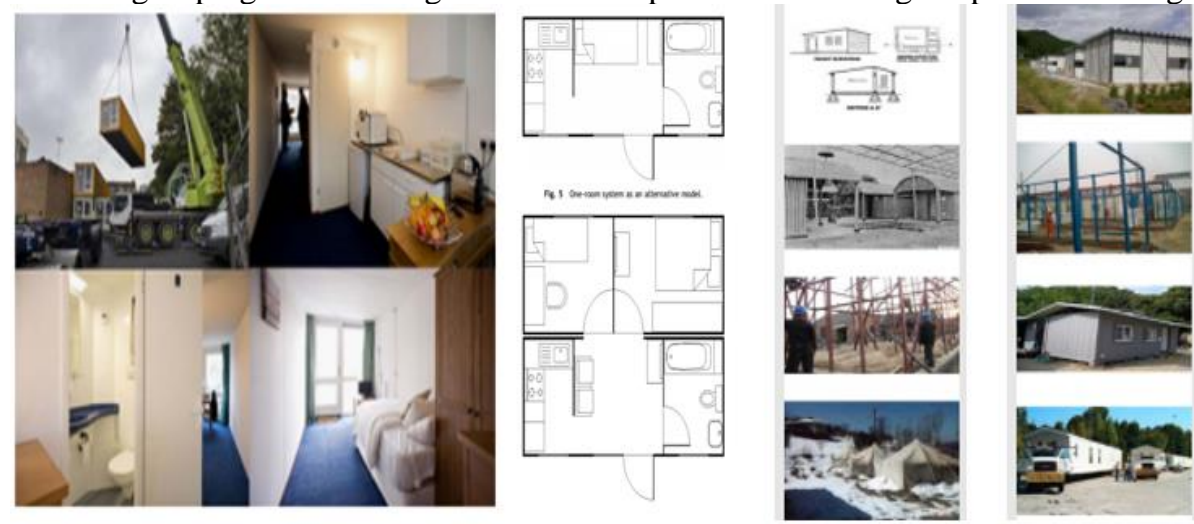

Fig 3. Refugee architecture and its types 


\section{The foundations of refugee architecture design}

Designing temporary buildings is a process of determinants and considerations of function, structure type, context, type of temporary usage and expected life cycle, and the design of temporary buildings is a skill gather requirements and restrictions, for example available materials and resources, budget issues, structural and operational concerns, maintenance and others. Finding temporary housing must take into consideration that each family represents a unique condition that has its own property, privacy, and diverse people. Also, in post-disaster conditions, some persons believed that this is not a significant principle because they want to provide ceilings for A large number of families, and this can be a solution in the emergency phase, but since they are heading towards a temporary phase that can last for a long period, families must be treated as sharing the same conditions. To achieve this requires, many changes should be applied to construct according to refugee architecture. These changes are related to several criteria that constitute the basis for assessing these types of buildings in displaced communities, and they include:

\subsection{The flexible of Capacity}

Although the goal of temporary housing buildings is to accommodate, determining the capacity is the first design consideration, as there are facilities that are defined in terms of capacity and that are produced by standard components that are not moving or that they are single masses factory-made, or that are flexible at the level of one building through the feature of site adaptation, or The possibility of expansion or modification as needed if the family continues to remain for a long period. finally, the tectonic structures that come from the factory as a single unit which combines the shell and the underlying structure in it, so it allows flexibility at the level of transportation only and not to the site adjustment. Temporary accommodation solutions have the essential settings to allow individuals go back to their regular activities such as housekeeping, socializing, going to school, etc., and there are two types that achieve flexibility in assembly to reach the appropriate capacity, see Figure 4: the first "Ready-made units" which are completely manufactured in the factory, and then transport to the specific place in the future, which may require a slight assembly work on site. The second "Kit supplies" by providing all the elements that make up the structure to be completely assembled on site. Regardless of the chosen model, temporary residential buildings tend to be as the permanent home by being more resistant and to provide basic infrastructure, such as water supply, sanitation, electricity, etc [8]. 


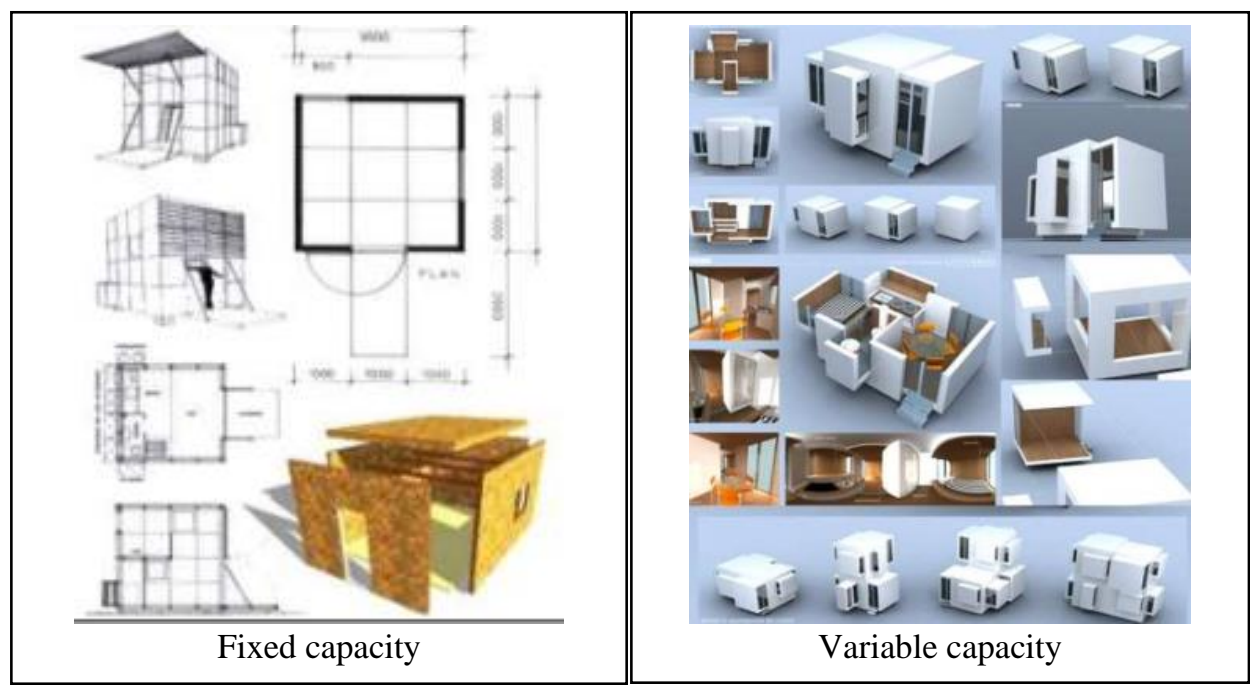

Fig.4. The flexible of Capacity

\subsection{Budget}

Construction cost is one of the dimensions that is not often far from the attentions of the building agents, project teams, builders, and quantity evaluators. In general, it includes capital costs and life cycle costs, and it is very important to focus on both of them at the same time. Temporary architecture clients in such cases after Disasters are the sufferers themselves or donations and the cost must be compact extremely, and there are several factors that affect the co budget of the temporary building as the priorities and the identity of the customer, the project nature and the person who is responsible for evolving its project, choosing purchase options, dominant market situations and legislative restrictions.

\subsection{Processing period}

The emergency phase of temporary buildings must be reduced as much as possible. Therefore, a strategy or framework must be developed to calm the victims and alleviate the pressure and suffering that they are exposed to rapidly. After creating the important infrastructure, the crucial point of this phase is housing construction as it is allowing to transport from the emergency phase to temporary. But there are several solutions to decrease the period of construction, like making these shelters in workshops while the substructure is taking place on-site and all we have to do is put it on the basis of which we have already done there. But in other cases, such as wars, it is not suitable as it possibly would be much expensive and shelters have to be transferred to the location and this adds more costs. Another solution is to let the victims themselves construct with a block or any other materials, but this usually takes an additional period [9]. 


\subsection{Durability, continuity and protection}

Durability is based on materials type and structural solution, and during the period of use, it should work well. Trusting temporary buildings requires thinking about its durability and its continuity as in some cases, this stage can last for a long time, so temporary buildings for shelters must to be durable for equal years. Some principles must take into consideration to recognize how the design of the temporary building is solid, primarily taking into account the main harsh environmental impact, because everything in nature is undergoing to natural diversity, and these are unavoidable but controllable. On the other hand, victims' comfort in their shelters is also an essential idea because living for a long time means that the family will have additional needs as in permanent housing. For example, "container" homes due to problems related to sunlight supply, ventilation, water, wastewater, insulation, and critical safety issues from fire, electricity, and shock dangers do not last long [10].

In temporary housing, the residence solutions must be considerate for the people who will live in them, and the buildings must be designed from the viewpoint of users in terms of social and technical aspects as well as symbols and approved patterns. Also, the external spaces surrounding the units must be well designed and organized and external areas of the units to be related to the establishment Achieving buffer zones between public spaces and the private area, which is necessary to create some privacy between neighborhoods.

\subsection{Sustainable building materials and systems}

In the design phase of producing this type of temporary building, choosing the right materials is crucial for the interior design. Poor choice of materials may reduce the quality of the project, and raise costs during the long-standing operation and conservation stages, and even exposing individuals and the environment to threat [11], through the adoption of materials that are more resistant to fires, pests and dust, and have adopted levels of sustainability in them from both renewable natural and non-renewable resources through reducing consumption, and reuse existing resources such as salvage, recycled content or recyclable materials [12]. In the field of energy, the choice of materials with thermal insulation is extremely important, because, in the area of temporary architecture, the issue differs from cities, because here we do not possess any of the infrastructures, or energy may be supplied by charitable institutions that may be discontinuous or stable. Therefore, it is good to adopt materials that conserve energy inside the building, whether in summer or winter.

Temporary housing units adopt simple construction systems and unit work must be easier and faster to improve speed, in addition, to allow for local manpower participation. The same way, the disassembly process is eased after use and facilitated to transport. When local funds are scarce or absent, imported components must then be the solution by adopting small and light components to transport effortlessly, especially when hard-to-reach areas. In terms of environmental issues, there is a necessity for more infrastructure and resource usage, as temporary residence strategies cause multi drawbacks with the future usage of elements when they were unnecessary. Temporary housing units often require repair after the intended use period. It is often simply disassembled without worrying about the upcoming use of components result, which is resource waste. moreover, the location of the components was placed frequently becomes polluted as it occasionally the compounds and infrastructure are not detached and the location is mess up in order to restore its basic condition as in the period of pre-disaster[13]. local resources usage is a better choice than foreign solutions to suit them socially, locally as well as has more economic benefit, because their familiarity and costs less for transportation, 
and the usage of local resources offers the possibility to participate the local staff in construction because they used to deal with it. So, victims' participation can be a valuable way to recover Feeling proud, relevant after shocking disaster actions. In the same way, many local building techniques can be more disaster-resistant when compared to some contemporary building methods, and local materials usage and building techniques allow individuals to make adjustments. This makes maintenance economical and easier, in order to advance the construction possibilities.

\section{The theoretical framework for the foundations of refugee architecture design:}

In this axis, a theoretical framework will be presented that introduces the items of assessing the temporary architecture of the displaced, and then it is applied to the academic cases:

\begin{tabular}{|c|c|c|c|}
\hline Main vocabulary & $\begin{array}{l}\text { Secondary } \\
\text { vocabulary }\end{array}$ & & ible values \\
\hline \multirow{7}{*}{$\begin{array}{l}\text { The flexible of } \\
\text { Capacity }\end{array}$} & \multirow{2}{*}{ Fixed capacity } & \multicolumn{2}{|c|}{ Producing standard components } \\
\hline & & \multicolumn{2}{|c|}{ Non-standard (single block) } \\
\hline & \multirow{5}{*}{$\begin{array}{l}\text { Variable- } \\
\text { capacity }\end{array}$} & \multirow[b]{2}{*}{ Single structure } & On the parts level. \\
\hline & & & $\begin{array}{l}\text { At the level of the hinge } \\
\text { sections }\end{array}$ \\
\hline & & \multirow{3}{*}{ Multiple structures } & $\begin{array}{c}\text { Transporting construction } \\
\text { pieces }\end{array}$ \\
\hline & & & Move the entire building \\
\hline & & & Tectonics (structure and skin) \\
\hline \multirow{4}{*}{ Budget } & \multirow{2}{*}{ Initial costs } & \multicolumn{2}{|c|}{ Material cost } \\
\hline & & \multicolumn{2}{|c|}{ Tools cost } \\
\hline & \multirow{2}{*}{ Life cycle costs } & \multicolumn{2}{|c|}{ Material cost } \\
\hline & & \multicolumn{2}{|c|}{ Tools cost } \\
\hline \multirow{4}{*}{ Possessing duration } & \multirow[b]{2}{*}{ Infrastructure } & \multicolumn{2}{|c|}{ single building } \\
\hline & & \multicolumn{2}{|c|}{ Camp-level } \\
\hline & \multirow{2}{*}{ Housing units } & Sites & By the institute \\
\hline & & Manufacturers & By the displaced. \\
\hline \multirow{5}{*}{$\begin{array}{l}\text { Durability, continuity } \\
\text { and protection }\end{array}$} & \multirow{3}{*}{$\begin{array}{l}\text { Resistant to } \\
\text { environmental } \\
\text { conditions }\end{array}$} & \multicolumn{2}{|c|}{ Temperature resistant } \\
\hline & & \multicolumn{2}{|c|}{ Windproof } \\
\hline & & \multicolumn{2}{|c|}{ Rainproof } \\
\hline & \multirow{2}{*}{ Resisting use } & & se once \\
\hline & & & ersatile \\
\hline \multirow{9}{*}{$\begin{array}{l}\text { Sustainable building } \\
\text { materials and systems }\end{array}$} & \multirow{2}{*}{$\begin{array}{l}\text { Quality of } \\
\text { materials }\end{array}$} & & umer items \\
\hline & & Hig & ting materials \\
\hline & \multirow{3}{*}{ Sustainability } & \multicolumn{2}{|c|}{ Extracted } \\
\hline & & \multicolumn{2}{|c|}{ Recyclable content } \\
\hline & & \multicolumn{2}{|c|}{ Recycling materials } \\
\hline & $\begin{array}{l}\text { Energy } \\
\text { efficiency }\end{array}$ & \multicolumn{2}{|c|}{ thermal insulation } \\
\hline & & & resistance \\
\hline & Safety & & eving safety \\
\hline & & & ion resistant \\
\hline
\end{tabular}




\section{Practical study}

Three specialized projects in Iraqi refugee camps were elected, each of which depends on a pattern of temporary housing units (tents, site construction, prefabricated building) for the purpose of showing the quality of their design, and the comparative descriptive-analytical measurement method will be adopted in its analysis, for the purpose of applying the vocabulary of the theoretical framework.

\subsection{Qushtaba Camp (Tents)}

This camp is located on the Erbil-Kirkuk Road in Iraqi Kurdistan. It was established on agricultural land, and the main services are supervised by the United Nations. There are currently 1819 tents in the camp, and tents are the eldest form of displacement as a result of disasters and wars due to its simple cost and speed of implementation, as it is possible to work with victims to install it. Here, the structure is built and then covered with a lid, and this takes a very short time. But this often means moving from temperate to harsh environments. If these shelters are used for a longer period than expected, the inhumane situation rises, as the shelter does not only relate to providing the physical structure; rather, they need to meet a number of other requirements, such as the authorities that are collected Within specific areas that may be difficult to reach during the very cold days[14], see Figure 2.

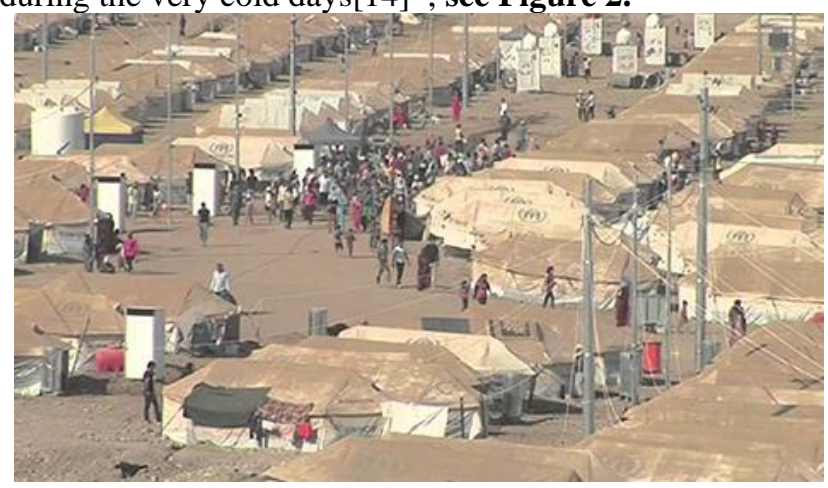

Fig. 2. Qushtaba camp in Iraqi Kurdistan

In addition, one of the main disadvantages of this pattern being that it is lightweight is that it is short-lived, as it is very influenced by environmental conditions over time, and neither the cover nor the structure can resist rain, storms or other external impacts. moreover, the absence of privacy of the family. As for the approved materials, they are made of steel or PVC, both of which are capable of reuse and recycling. After the use is completed, we can dismantle and store it for the next task, or we can recycle it for new usages. As for its capacities, multi models are produced and given to individuals who will be accommodated in that tent. However, a tent is usually produced as a standard for a family of five, and here no additional spaces can be added[15]. 


\subsection{Darashkran camp (on-site construction)}

The camp is located in the north of Erbil after the Japanese Wings of Peace Organization PWJ in August 2018, built temporary housing units with up to 800 units, characterized by being safer and resistant to natural conditions, weather threats and extreme coldness, and these temporary units depend on the method of site construction. Here, there is no problem in finding its materials, because it uses easily available natural materials. Ground buildings constructed by an intermediate technology and afford an alternative to both contemporary and traditional techniques, and they are permanent and their implementation is common, so it does not require much experience, and the workforce can be the population themselves [16]. All over the world, there are many refugee families, who find this method suitable for building housing that meets their basic needs, taking into consideration their environmental surroundings, because it gives good and healthy interior properties that improve the comfort of their residents, see Figure 3.

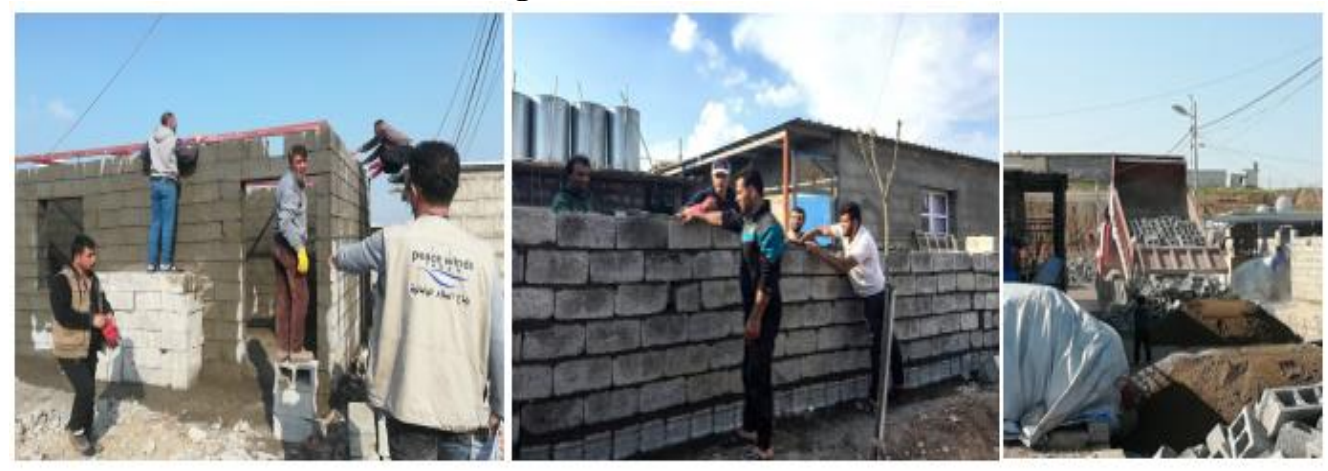

Fig. 3. Darashkran camp in Iraqi Kurdistan

Although the speed of transporting materials or any other equipment as a result of its products locally, the construction process in these buildings often takes a relatively long period and varies depending on the construction type. It is also probable to shape furniture, such as seats and couches, or even places or bookshelves that may help decrease costs because there is not essential to purchase them elsewhere, and this condition can take place even after house accomplishment. This system provides a very long period of use. As for its materials, many advantages are found compared to foreign materials like low prices, local natural resources, and considering this type of shelter very energy-efficient. Initially, the main construction process can be accomplished without any need for energy. On the other hand, its walls are thickened, which makes the interior environment comfortable, and the temperatures inside the spaces are completely stable [17].

ground buildings flexibility depends on the construction technique. This method allows for other structural additions even after the construction is completed and others can be rebuilt to modify the design. However, in both cases, this process will not cost more than an additional simple and available material, and this is a great benefit here. In addition, these housing can have many rooms and it is possible to install water infrastructure and apply several technologies 
to save and recycle it. Finally, many of the displaced people in this camp preferred to consider these units permanent for them, especially those with limited income[18].

\subsection{Mamarshan Camp (Prefabricated Shelters)}

In order to improve the living conditions of IDPs, who live in shelters outside camps in Dohuk Governorate, the BRHA and $\mathrm{WHH}^{1}$ organizations have completed a project to develop 295 prefabricated housing units, which aim to better use for resources and improve control over them, see Figure 4. All construction works use Modular units such as walls, tributaries and windows, which are partial or total prefabricated, and which are produced by central factories[19]. This type of industrialization can be adopted in unindustrialized nations, as it uses local materials and avert industrial processes with advance technology, but it costs a lot, which makes it difficult to provide them with low incomes, including donations, and usually, this type of shelters is produced through the support of governments. The processing time is small. Moreover, the on-site treatment will not exceed a few hours. Here the infrastructure must be set up (such as power and water equipment) for each shelter, then just to place the shelter and attach the extensions.

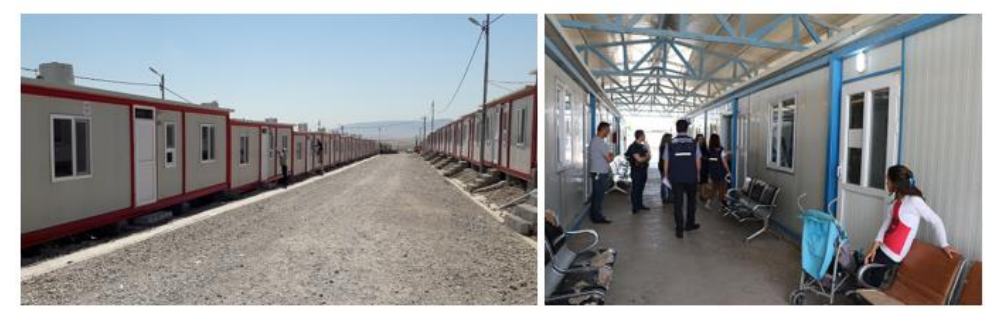

Fig. 4. Accreditation of the measuring units in the Mamarshan camp

prefabricated shelters have a longer usage period compared to other temporary architecture structures. Because of its materials, it can last for a long period without requiring replacement or repair. It is beneficial for each environment, and it can be formed to suit any area in the world, which makes it a global option as sustainable temporary architecture. otherwise, when it is no longer needed, it can be dismantled and reused elsewhere with equal efficiency. As for the materials in the prefabricated structures, they allow many innovations that make them one of their most important features[20]. Here when making Maoists at the factory, there is a large number of materials available for selection that depend on the budget and the climate. the most common in post-disaster situations are the mixtures that reach thermal isolation, fire resistance, low carbon emissions, and zero waste, which are recycled and not affected by external impacts. As a thermal insulation material is used, it will reduce the heat that will run out of the building's housing. Energy can also be delivered to the shelter through the use of green resources such as wind, solar energy, or any sustainable resource. In addition, the possibility of adding a solar system to each shelter, which makes it an independent unit or applies a general system for green energy through an external network that links with the shelter complex.

1 - BRHA (Board of Relief and Humanitarian Affairs), WHH (welt hunger hilfe) humanitarian organization has many IDPs project in Iraq 
Moreover, there are many different components that can be used as Meccano to create the best design, dimensions and space to suit every situation[21].

\begin{tabular}{|c|c|c|c|c|c|c|}
\hline \multicolumn{4}{|c|}{ The foundations of refugee architecture design } & \multicolumn{3}{|c|}{ Elected projects } \\
\hline $\begin{array}{l}\text { Main } \\
\text { vocabulary }\end{array}$ & $\begin{array}{l}\text { Secondary } \\
\text { vocabulary }\end{array}$ & \multicolumn{2}{|c|}{ Possible values } & Tents & $\begin{array}{c}\text { On } \\
\text { ground } \\
\text { building }\end{array}$ & $\begin{array}{c}\text { Pre- } \\
\text { fabricated } \\
\text { building } \\
\end{array}$ \\
\hline \multirow{7}{*}{$\begin{array}{l}\text { Capacity } \\
\text { flexibility }\end{array}$} & \multirow{2}{*}{$\begin{array}{l}\text { Fixed } \\
\text { capacity }\end{array}$} & \multicolumn{2}{|c|}{$\begin{array}{l}\text { Producing standard } \\
\text { components }\end{array}$} & $*$ & & \\
\hline & & \multicolumn{2}{|c|}{ Non-standard (single block) } & & * & \\
\hline & \multirow{5}{*}{$\begin{array}{l}\text { Variable } \\
\text { capacity }\end{array}$} & \multirow{2}{*}{$\begin{array}{l}\text { Single } \\
\text { structure }\end{array}$} & $\begin{array}{c}\text { On the parts } \\
\text { level. }\end{array}$ & & & \\
\hline & & & $\begin{array}{l}\text { At the level of } \\
\text { the hinge } \\
\text { sections }\end{array}$ & & $*$ & $*$ \\
\hline & & \multirow{3}{*}{$\begin{array}{l}\text { Multiple } \\
\text { structure }\end{array}$} & $\begin{array}{l}\text { Transporting } \\
\text { construction } \\
\text { pieces }\end{array}$ & * & & * \\
\hline & & & $\begin{array}{c}\text { Move the } \\
\text { entire building }\end{array}$ & & & * \\
\hline & & & $\begin{array}{c}\text { Tectonics } \\
\text { (structure and } \\
\text { skin) }\end{array}$ & & & \\
\hline \multirow{4}{*}{ Budget } & \multirow{2}{*}{ Initial costs } & \multicolumn{2}{|c|}{ Material cost } & & $*$ & * \\
\hline & & \multicolumn{2}{|c|}{ Tools cost } & $*$ & & $*$ \\
\hline & \multirow{2}{*}{$\begin{array}{l}\text { Life cycle } \\
\text { costs }\end{array}$} & \multicolumn{2}{|c|}{ Material cost } & $*$ & & \\
\hline & & \multicolumn{2}{|c|}{ Tools cost } & & & * \\
\hline \multirow{4}{*}{$\begin{array}{l}\text { Possessing } \\
\text { period }\end{array}$} & \multirow{2}{*}{$\begin{array}{l}\text { Infra- } \\
\text { structure }\end{array}$} & \multicolumn{2}{|c|}{ single building } & $*$ & $*$ & \\
\hline & & \multicolumn{2}{|c|}{ Camp-level } & $*$ & * & $*$ \\
\hline & \multirow{2}{*}{$\begin{array}{l}\text { residential } \\
\text { units }\end{array}$} & Sites & $\begin{array}{l}\text { By The } \\
\text { institute }\end{array}$ & & $*$ & \\
\hline & & $\begin{array}{c}\text { Manufact } \\
\text { urers }\end{array}$ & $\begin{array}{c}\text { By the } \\
\text { displaced. }\end{array}$ & * & & * \\
\hline \multirow{5}{*}{$\begin{array}{l}\text { Durability, } \\
\text { continuity and } \\
\text { protection }\end{array}$} & \multirow{3}{*}{$\begin{array}{l}\text { Resistant to } \\
\text { environment } \\
\text { al conditions }\end{array}$} & \multicolumn{2}{|c|}{ Temperature resistant } & & $*$ & $*$ \\
\hline & & \multicolumn{2}{|c|}{ Wind proof } & & $*$ & $*$ \\
\hline & & \multicolumn{2}{|c|}{ Rain proof } & & $*$ & $*$ \\
\hline & \multirow{2}{*}{$\begin{array}{c}\text { Resisting } \\
\text { use }\end{array}$} & \multicolumn{2}{|c|}{ Use once } & $*$ & $*$ & \\
\hline & & \multicolumn{2}{|c|}{ Versatile } & $*$ & & $*$ \\
\hline & Quality of & Con & mer items & * & * & \\
\hline & materials & High-la & ing materials & $*$ & & $*$ \\
\hline & & & tracted & & & $*$ \\
\hline & Sustainabilit & Recyc & ble content & & & $*$ \\
\hline building & & Recyc & ag materials & & & * \\
\hline $\begin{array}{l}\text { materials and } \\
\text { systems }\end{array}$ & $\begin{array}{c}\text { Energy } \\
\text { efficiency }\end{array}$ & therm & insulation & & & $*$ \\
\hline & & Fire & esistance & & $*$ & $*$ \\
\hline & Safety & Achi & jing safety & & $*$ & \\
\hline & & Pollu & on resistant & & $*$ & $*$ \\
\hline
\end{tabular}




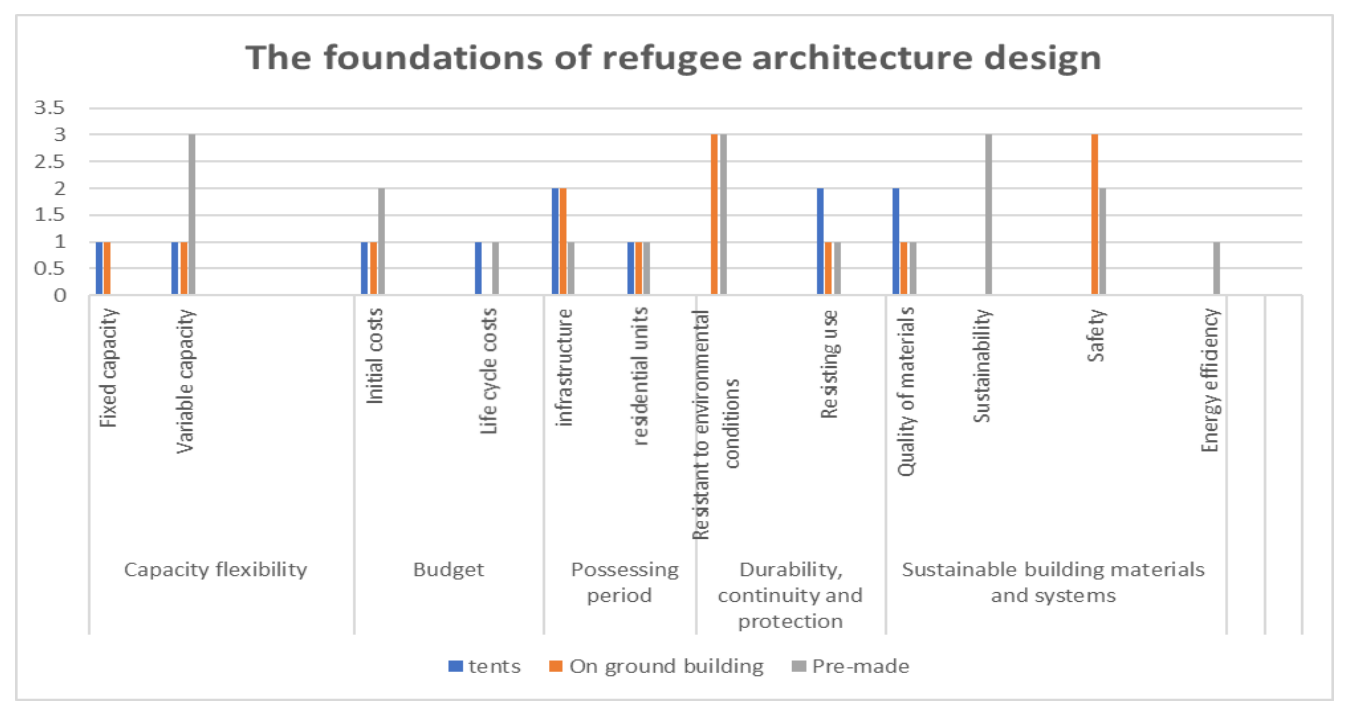

\section{Conclusions}

Temporary architecture has a crucial role after a disaster and can be implemented easily and efficiently through the adoption of the appropriate architecture.

there are temporary units that do not meet the need properly, because what could be an effective means of disaster management can become a crisis with Many negative consequences require a lot of investment and planning to deal with it.

One of the most important pillars of temporary architecture is achieving flexibility in capacity for its ability to accommodate changes that occur as a result of crises.

Tents is not an appropriate option for a sustainable solution, but it is better in the emergency phase because its shortest treatment period and can be carried out by the victims themselves. Temporary housing units must observe the protection aspects, i.e. resistance to offer adequate safety from outside aspects, such as wind, snow, rain, temperatures, etc.

Necessary dimensions should be taken into consideration in the temporary housing units, these have to suit the requirements of each family and enable different layouts to allow differences according to the size of families.

The shelter should Provide privacy, comfort, indoor, lighting, ventilation, natural and artificial temperature, etc.

Propose possible solutions in advance for the units after period of use, by adopting Alternatives for reuse for the same or different purpose.

recycling are extremely beneficial solutions as they are not contaminated, by using the most environmentally friendly technologies and materials to avoid environmental pollution.

Flexible solutions must be adopted in terms of space and a variety of configurations that give victims an opportunity to use the unit as a multifunctional space, as well as facilitate transformations and adjustments. It also makes it easier for users to customize the unit, which helps them feel more related to their shelters. 


\section{References}

[1] www.merriam-webster.com.

[2] Kim, D.: Adaptive Reuse of Industrial Buildings for Sustainability. pp. 9-10. Thesis. US. (2018).

[3] https://repository.up.ac.za/bitstream/handle/2263/30282/02chapter2.pdf?sequence=3\&isAllowed=y

[4] Mohamed, H.: The effect of digital interactivity on the architectural characteristics of interior space.

Thesis. p.18. (2015).

[5] Duksi, A.: Sustainable Temporary Architecture. Thesis. pp.13-14. Turkey. (2016).

[6] Kronenburg. R.: Flexible. Architecture that Responds to Change. pp.13-14. UK. (2007).

[7] Bologna, R.: Transitional housing for emergencies: temporariness and reversibility of building process. Florence. pp.1-3. (2008).

[8] Bologna, R.: Transitional housing for emergencies: temporariness and reversibility of building process. Florence. pp.6-7. (2008).

[9] Duksi, A.: Sustainable Temporary Architecture. Thesis. p.15. Turkey. (2016).

[10] Hong, Y.: A study on the condition of temporary housing following disasters: Focus on container housing. Article. China. (2017).

[11] Zhang, A.: Comprehensive Method for the Selection of Sustainable Materials for Building

Construction, the Faculty of Worcester Polytechnic Institute. Thesis. p.ii. (2012).

[12] Tomkiewicz, H.: Barriers to Implementation of Sustainable Construction Practices in the

Homebuilding Industry- A Case Study of Rochester. Nebraska-Lincoln. Thesis. p.27. Nebraska. (2011).

[13] Ting, S.: Optimization of Embodied Energy in Domestic Construction. RMIT University. p.3. (2006).

[14] https://harmoon.org/

[15] Axelsson, F.: The Emergency Housing Project, Chalmers. 2012.

[16] https://peace-winds.org/en/news/1979.

[17] https://www.btibd.com/advantages-of-using-concrete-hollow-blocks-an-innovation-in-buildingproducts/.

[18] https://peace-winds.org/en/news/1979.

[19] http://www.brha-duhok.org/mamrashan-camp

[20] Duksi, A.: Sustainable Temporary Architecture. Thesis. pp.21-22. Turkey. (2016).

[21] Lizarralde, G., Davidson, C., Johnson, C.: Myths and Realities of Prefabrication for Post Disaster Reconstruction. 4th International i-Rec. pp.1-3. New Zealand. (2008). 